\section{Kodaikanal Observatory: Report for 1953}

IN the annual report of the Kodaikanal Observatory for the year 1953 (pp. 10. Delhi : Manager of Publications, 1954 ; As. 9 or $10 d$.), A. K. Das, the director of the Observatory, deals chiefly with the astronomical work. International co-operation with other observ atories continues, and exchanges have been carried out with the Royal Greenwich Observatory, the Observatories of the University of Cambridge, Meudon Observatory, and Mount Wilson Observatory. Quarterly statements relating to solar flares were sent as usual to the Royal Greenwich Observatory and Meudon Observatory. The lists of instruments are classified under five headings: astronomical and spectroscopic instruments, of which thirty-three are catalogued; magnetic, with a total of eight; electronic, including nineteen; workshop machinery, eleven; and under other instruments, of which six are listed; but various other instruments not catalogued, such as galvanometers, photocells, thermorelays, etc., are also available. Details of sunspot activity-spots, prominences, with the Doppler shifts of the $\mathrm{H} \alpha$ line observed in prominences, heights of prominences, etc., are shown in tabular form. Under the research training scheme sponsored by the Ministry of Education of the Government of India, two senior and two junior scholars were working in the Observatory. A list of publications-seventeen altogether-during the year is given at the end of the report.

\section{Council for the Promotion of Field Studies:} Summer Courses

A POPULAR belief that the courses organized by the Council for the Promotion of Field Studies are confined to the summer months is discounted by the issue of the programme setting out the arrangements at each of the field centres of the Council during the autumn. All the usual courses in marine and freshwater biology, geography and general natural history, rural studies and entomology are being continued, while, in addition, each centre is arranging courses to suit more specialist interests. At Malham Tarn, for example, a short course in meteorology is being arranged during August 24-31, the directors being Dr. C. D. Ovey (University of Cambridge) and Dr. R. S. Scorer (Imperial College of Science and Technology, London). A week's course in surveying and map-making will be held at Juniper Hall during August 10-17, while courses in the identification and ecology of lichens as well as one on local mosses are being organized at Malham Tarn. A week devoted to the study of fungi is planned for Flatford Mill during September 21-28, while Dale Fort is to hold a course, limited to twelve students, on oceanography during August 24-31. The pamphlet giving the details of these courses is obtainable from the Council at Ravensmead, Keston, Kent, or from any of the above-mentioned field centres.

Forests of the Upper Nile Province, Sudan, 18621950

It is becoming apparent that under the Sudanization plan a large number of the British officials left in the Sudan Administration have decided to resign. In the case of the Forest Department, it is to be hoped that this will not result in a serious setback to the excellent work of the past eight years or so (see the annual report for 1951-52, reviewed in Nature, 173,903 ; 1954). The good work of past years is further exemplified by Memoir No. 5 of the
Sudanese Forestry Division, Ministry of Agriculture, entitled "Forests of Upper Nile Province, 18621950", by G. A. Booth (Khartoum, 1952). This brochure, which has excellent illustrations, is a most valuable piece of research work. After a reference to the evidence of Roman explorers and archæological evidence that the belt of high forest which stretched over Central Africa once extended as far north as Khartoum, Mr. Booth sets himself to examine how far in the provinces the forests have been overcut to supply the large demands for wood fuel made both by the towns and the river steamers since Sir Samuel Baker's time in the $1860^{\prime}$ s. It is too early to be able to agree with Mr. Booth's suggestion that possibly the supposed overcutting of the scattered forests to supply this growing demand for fuel has not seriously affected the forests on the areas from which the fellings were made.

\section{University of Birmingham}

IN the University of Birmingham the title of reader in analysis in the Department of Mathematics has been given to Dr. B. Kuttner, and that of reader in myeology in the Department of Botany to Dr. C. J. Hickman. The following have been appointed lecturers in the University: Dr. G. W. Hutchinson (physics), Dr. T. S. West (chemistry), R. Humphreys (civil engineering), Dr. Ingeborg. Gurland (education-child development) and C. J. Phillips (education-psychology).

A postgraduate course in coal preparation leading to the degree of M.Sc. by examination has been established in the University; the course will consist of lectures and laboratory and tutorial classes during the normal session, and will be followed by a project carried out on an industrial coal-preparation plant or on the pilot plant of a manufacturer of coal-preparation appliances.

In the Department of Pharmacology a grant of $£ 1,500$ a year for three years has been given by Quaker Oats, Ltd., for research into the chemistry and nutritional value of cereals.

\section{Zoological Publications of W. D. Selensky}

Prof. M. C. Meyer, professor of zoology in the University of Maine, writes to say that after considerable searching he finally obtained from abroad a copy of Waldimir D. Selensky's "Etudes morphologiques et systématiques sur les Hirudinées : I. L'Organisation des Ichthyobdellides", published in Leningrad (then called Petrograd) in 1915 (pp. viii + 246, 41 fig. +8 plates; in Russian). A photostatic copy was made, and afterwards a complete translation of the text was arranged. At the time of his death in 1931 Prof. Selensky was a leading zoologist in the U.S.S.R., being head of the Parasitological Department, University of Leningrad, and his researches were devoted chiefly to the morphology, biology and the systematics of leeches, the most important contribution being the above-mentioned publication. Museum and university librarians interested in obtaining a copy of the English trans. lation, with text-figures and plates, should write to Prof. Marvin C. Meyer, Department of Zoology, University of Maine, Orono, Maine.

\section{Colonial Service : Recent Appointments}

ThE following appointments have recently been made in the Colonial Service: D. D. Campbell (agricultural officer, Uganda), principal agricultural officer, Basutoland; R. G. Heath (deputy director 